\title{
SYARAT PERLU DAN SYARAT CUKUP KEBERADAAN DAN KETUNGGALAN KESEIMBANGAN NASH CAMPURAN SEMPURNA PADA BIMATRIX GAMES
}

\author{
ANGGI MUTIA SANI \\ Program Studi Matematika, \\ Fakultas Matematika dan Ilmu Pengetahuan Alam, Universitas Andalas, \\ Kampus UNAND Limau Manis Padang, Indonesia, \\ mutiasani.anggi@gmail.com
}

\begin{abstract}
In this paper, the necessary and sufficient condition for the existence and uniqueness of a completely mixed Nash equilibrium in bimatrix games $\left[A, A^{T}\right]$ are presented. Matrix $A \in \mathbb{R}^{n \times n}$ is a payoff matrix. The necessary and sufficient condition are expressed with some properties of saddle point matrices, denoted by $(A, \mathbf{e})$, where $\mathbf{e}$ is the column vector with all entries 1 . Properties of the saddle point matrices assessed using the algebraic approach.
\end{abstract}

Kata Kunci: Nash Equilibrium, bimatrix games, matrix payoff, saddle point matrix.

\section{Pendahuluan}

Teori permainan (game theory) merupakan suatu pendekatan matematis untuk merumuskan situasi persaingan dan konflik antara berbagai kepentingan. Teori ini menjadi topik yang banyak mendapat perhatian karena dapat mengembangkan suatu metode sistematis yang memungkinkan para pemain yang terlibat dalam persaingan, memilih strategi-strategi yang terbaik dalam pencapaian tujuan mereka.

Dalam suatu permainan, hal yang paling penting diperhatikan adalah banyak pemain, besar pembayaran, dan strategi yang akan digunakan. Di sini akan dibahas permainan yang melibatkan dua pemain.

Agar dalam suatu persaingan terjadi keseimbangan, dimana tidak ada pemain yang bisa memperoleh keuntungan dengan mengubah strateginya, sedangkan pemain lain menjaga strategi mereka agar tidak berubah, maka kajian yang akan dibahas dalam penulisan ini yaitu syarat perlu dan syarat cukup keberadaan dan ketunggalan keseimbangan Nash campuran sempurna pada bimatrix games.

Untuk mengkaji syarat perlu dan syarat cukup keberadaan dan keseimbangan Nash campuran sempurna, digunakan sifat-sifat dari suatu matriks yang disebut matriks saddle point.

Matriks saddle point ini dinotasikan dengan $(A, \mathbf{e})$, yang didefinisikan dalam bentuk matriks blok sebagai berikut: $(A, \mathbf{e})=\left(\begin{array}{cc}A & \mathbf{e} \\ \mathbf{e}^{t} & 0\end{array}\right)$. Blok kiri atas adalah matriks $A \in \mathbb{R}^{n \times n}$ yang merupakan matriks pembayaran untuk pemain pertama, blok kanan atas adalah vektor kolom e dengan semua entri-entrinya adalah 1. 


\section{Teori Permainan}

Pada makalah ini akan dibahas permainan yang menggunakan stategi campuran. Suatu strategi campuran adalah suatu vektor peluang kolom $\mathbf{y}=\left(q_{j}\right)$ dimana $q_{j}$ merupakan peluang digunakannya strategi ke- $j$. Jika kemungkinannya strictly positive, y dikatakan campuran sempurna. Keseimbangan Nash campuran sempurna adalah suatu keseimbangan Nash dimana strategi - strategi kedua pemain adalah campuran sempurna.

Setiap pemain yang kalah, harus membayar kepada pemain yang menang, yang dapat digambarkan dalam suatu matriks yang disebut matriks pembayaran (matrix payoff), yaitu matriks yang menyatakan pembayaran yang bersesuaian dengan strategi setiap pemain. Entri-entri pada matriks pembayaran tersebut, dideskripsikan dalam bentuk bimatrix games. Suatu bimatrix games diberikan dalam bentuk pasangan terurut $[A, B]$ dari matriks pembayaran, $A=\left(a_{i j}\right)$ dan $B=\left(b_{i j}\right)$. Matriks $A$ adalah suatu matriks pembayaran untuk pemain pertama dan matriks $B$ adalah suatu matriks pembayaran untuk pemain kedua. Pembayaran yang diharapkan dari permainan, dinotasikan dengan $u(A)$, didefinisikan dengan $u(A)=\mathbf{e}^{T} A \mathbf{y}$, dimana $A$ adalah matriks pembayaran yang dilakukan pemain pertama.

Jika pemain pertama dan pemain kedua berturut-turut memilih strategi ke$i$ dan ke- $j$, maka pembayaran pemain pertama adalah $a_{i j}$ dan pembayaran pemain kedua adalah $b_{i j}$.

\section{Pembahasan}

Pada pembahasan ini, digunakan sifat-sifat matriks saddle point untuk mengkaji syarat perlu dan syarat cukup keberadaan dan ketunggalan keseimbangan Nash campuran sempurna pada bimatrix games. Matriks yang diperoleh dari matriks $A$ dengan cara mengganti baris ke- $i$ dengan $\mathbf{e}^{T}$, dinotasikan dengan $A^{i}$. Sedangkan $A_{j}$ diperoleh dengan cara mengganti kolom ke- $j$ dengan e.

Proposisi 3.1. Misalkan $A \in \mathbb{R}^{n \times n}, n>1$. Untuk sebarang matriks $A$ berlaku persamaan:

$$
\operatorname{det}(A, \boldsymbol{e})=-\sum_{i=1}^{n} \operatorname{det}\left(A^{i}\right)=-\sum_{j=1}^{n} \operatorname{det}\left(A_{j}\right)
$$

Bukti. Dengan menggunakan ekspansi kofaktor, diperoleh

$$
\begin{aligned}
\operatorname{det}(A, \mathbf{e}) & =\operatorname{det}\left(\begin{array}{cc}
A & \mathbf{e} \\
\mathbf{e}^{T} & 0
\end{array}\right) \\
& =\operatorname{det}\left(\begin{array}{ccccccc}
a_{11} & a_{12} & \cdots & a_{i j} & \cdots & a_{1 n} & 1 \\
a_{21} & a_{22} & \cdots & a_{2 j} & \cdots & a_{2 n} & 1 \\
\vdots & \vdots & \ddots & \vdots & \ddots & \cdots & \vdots \\
a_{n 1} & a_{n 2} & \cdots & a_{n j} & \cdots & a_{n n} & 1 \\
1 & 1 & \cdots & 1 & \cdots & 1 & 0
\end{array}\right)
\end{aligned}
$$




$$
=\sum_{j=1}^{n}(-1)^{n+1+n-1} \operatorname{det}\left(\begin{array}{cccccc}
a_{11} & a_{12} & \cdots & a_{1 n-2} & a_{1 n} & 1 \\
a_{21} & a_{22} & \cdots & a_{1 n-2} & a_{2 n} & 1 \\
\vdots & \vdots & \ddots & a_{1 n-2} & \vdots & \vdots \\
a_{n 1} & a_{n 2} & \cdots & a_{1 n-2} & a_{n n} & 1
\end{array}\right) .
$$

Misalkan $M_{i j}=\left(\begin{array}{cccccc}a_{11} & a_{12} & \cdots & a_{1 n-2} & a_{1 n} & 1 \\ a_{21} & a_{22} & \cdots & a_{1 n-2} & a_{2 n} & 1 \\ \vdots & \vdots & \ddots & a_{1 n-2} & \vdots & \vdots \\ a_{n 1} & a_{n 2} & \cdots & a_{1 n-2} & a_{n n} & 1\end{array}\right)$.

Dengan menggunakan hukum determinan pergantian kolom, di mana jika $N$ adalah suatu matriks yang diperoleh dari matriks $A$ dengan menukarkan dua baris dari matriks $A$, maka $\operatorname{det}(N)=-\operatorname{det}(A)$. Hal ini mengikuti bentuk $A_{j} \operatorname{dimana} A_{j}$ adalah matriks yang diperoleh dari matriks $A$ dengan cara mengganti kolom ke- $j$ dengan e. Kolom yang memuat e pada matriks $M_{i j}$ adalah kolom ke- $n$. Sehingga, dengan menggunakan hukum determinan pergantian kolom, diperoleh

$$
\sum_{j=1}^{n}(-1)^{2 n} \operatorname{det}\left(\begin{array}{cccccc}
a_{11} & a_{12} & \cdots & a_{1 n-2} & a_{1 n} & 1 \\
a_{21} & a_{22} & \cdots & a_{1 n-2} & a_{2 n} & 1 \\
\vdots & \vdots & \ddots & a_{1 n-2} & \vdots & \vdots \\
a_{n 1} & a_{n 2} & \cdots & a_{1 n-2} & a_{n n} & 1
\end{array}\right)=-\sum_{j=1}^{n} \operatorname{det}\left(A_{j}\right)
$$

Proposisi 3.2. Misalkan $A, E \in \mathbb{R}^{n \times n}, n>1$ dan $E=e^{T}$. Untuk sebarang bilangan riil $\alpha, \beta$, berlaku

$$
\operatorname{det}(\alpha A+\beta E, \boldsymbol{e})=\alpha^{n-1} \operatorname{det}(A, \boldsymbol{e}) .
$$

Bukti. Jika $\alpha=0$, maka jelas bahwa Proposisi 3.2 benar. Jika $\alpha \neq 0$, maka

$$
\begin{aligned}
& \operatorname{det}(\alpha A+\beta E, \mathbf{e})=\operatorname{det}\left(\begin{array}{cr}
\alpha A+\beta E \mathbf{e} \\
\mathbf{e}^{T} & 0
\end{array}\right) \\
& =\operatorname{det}\left(\begin{array}{cr}
\alpha A+\beta E \mathbf{e} \\
\mathbf{e}^{T} & 0
\end{array}\right)+\operatorname{det}\left(\begin{array}{cc}
-\beta \mathbf{e} \cdot \mathbf{e}^{T} & -\beta \mathbf{e} \cdot 0 \\
\mathbf{e}^{T} 0 & 0
\end{array}\right) \text {. }
\end{aligned}
$$

Karena $\operatorname{det}\left(\begin{array}{cc}-\beta \mathbf{e} \cdot \mathbf{e}^{T}-\beta \mathbf{e} \cdot 0 \\ \mathbf{e}^{T} 0 & 0\end{array}\right)=0$, maka

$$
\begin{aligned}
\operatorname{det}(\alpha A+\beta E, \mathbf{e}) & =\operatorname{det}\left(\begin{array}{cr}
\alpha A+\beta E \mathbf{e} \\
\mathbf{e}^{T} & 0
\end{array}\right)+\operatorname{det}\left(\begin{array}{cc}
-\beta E & \mathbf{e} 0 \\
\mathbf{e}^{T} 0 & 0
\end{array}\right) \\
& =\operatorname{det}\left(\begin{array}{cc}
\alpha A & \mathbf{e} \\
\mathbf{e}^{T} & 0
\end{array}\right) .
\end{aligned}
$$


Karena $\operatorname{det}(\alpha A)=\alpha^{n} \operatorname{det}(A)$, maka

$$
\begin{aligned}
\operatorname{det}(\alpha A+\beta E, \mathbf{e}) & =\operatorname{det}\left(\begin{array}{cc}
\alpha A & \mathbf{e} \\
\mathbf{e}^{T} & 0
\end{array}\right), \\
& \left.=\operatorname{det}\left[\begin{array}{cc}
\alpha A & \frac{1}{\alpha} \mathbf{e} \\
\frac{1}{\alpha} \mathbf{e}^{T} & 0
\end{array}\right)\right], \\
& =\alpha^{n+1} \operatorname{det}\left(\begin{array}{cc}
A & \frac{1}{\alpha} \mathbf{e} \\
\frac{1}{\alpha} \mathbf{e}^{T} & 0
\end{array}\right), \\
& =\alpha^{n} \operatorname{det}\left(\begin{array}{cc}
A & \mathbf{e} \\
\frac{1}{\alpha} \mathbf{e}^{T} & 0
\end{array}\right), \\
& =\alpha^{n-1} \operatorname{det}\left(\begin{array}{cc}
A & \mathbf{e} \\
\mathbf{e}^{T} & 0
\end{array}\right), \\
& =\alpha^{n-1} \operatorname{det}(A, \mathbf{e}) .
\end{aligned}
$$

Proposisi 3.3. Misalkan $A, E \in \mathbb{R}^{n \times n}, n>1$ dan $E=e e^{T}$. Untuk setiap bilangan riil $\alpha, \beta$, berlaku

$$
\operatorname{det}(\alpha A+\beta E)=\alpha^{n-1}[\alpha \operatorname{det}(A)-\beta \operatorname{det}(A, \boldsymbol{e})] .
$$

Bukti. Akan ditunjukkan bahwa $\forall \alpha A \in \mathbb{R}^{n \times n}$,

$$
\operatorname{det}(\alpha A+\beta E)=\operatorname{det}(\alpha A)-\beta \operatorname{det}(\alpha A, \mathbf{e}) .
$$

Dengan menggunakan hukum determinan, diperoleh bahwa turunan $\operatorname{det}(\alpha A+\beta E)$ terhadap $\beta$ adalah sebagai berikut:

$$
\frac{d[\operatorname{det}(\alpha A+\beta E)]}{d \beta}=\sum_{i=1}^{n} \operatorname{det}(\alpha A+\beta E)_{i} .
$$

Turunan entri-entri pada baris ke- $i$ dari matriks $\alpha A+\beta E$ terhadap $\beta$ semuanya 1 . Hal ini mengikuti bentuk matriks $(\alpha A+\beta E)^{i}$, yaitu matriks yang diperoleh dari matriks $\alpha A+\beta E$ dengan cara mengganti baris ke- $i$ dengan $\mathbf{e}^{T}$. Sehingga dapat ditulis

$$
\frac{d[\operatorname{det}(\alpha A+\beta E)]}{d \beta}=\sum_{i=1}^{n} \operatorname{det}(\alpha A+\beta E)^{i} .
$$

Dengan menghitung determinan dari matriks $(\alpha A+\beta E)^{i}$, diperoleh

$$
\begin{aligned}
\frac{d[\operatorname{det}(\alpha A+\beta E)]}{d \beta} & =\sum_{i=1}^{n} \operatorname{det}(\alpha A)^{i}, \\
& =-\operatorname{det}(\alpha A, \mathbf{e}) .
\end{aligned}
$$

Selanjutnya,

$$
\begin{aligned}
\operatorname{det}(\alpha A+\beta E) & =-\int \operatorname{det}(\alpha A, \mathbf{e}) d \beta, \\
& =-\beta \operatorname{det}(\alpha A, \mathbf{e})+k
\end{aligned}
$$


Untuk menghitung nilai $k$, pilih $\beta=0$, sehingga diperoleh $k=\operatorname{det}(\alpha A)$ untuk suatu konstanta $k$. Selanjutnya,

$$
\begin{aligned}
\operatorname{det}(\alpha A+\beta E) & =\operatorname{det}(\alpha A)-\beta \operatorname{det}(\alpha A, \mathbf{e}), \\
& =\alpha^{n} \operatorname{det}(A)-\beta \alpha^{n-1} \operatorname{det}(A, \mathbf{e}) \\
& =\alpha^{n-1}[\alpha \operatorname{det}(A)-\beta \operatorname{det}(A, \mathbf{e})] .
\end{aligned}
$$

Akibat 3.4. Misalkan $A, E \in \mathbb{R}^{n \times n}, n>1$ dan $E=e^{T}$. Determinan dari $(A, e)$ dapat dinyatakan sebagai berikut:

$$
\operatorname{det}(A, \boldsymbol{e})=\operatorname{det} A-\operatorname{det}(A+E) .
$$

Bukti. Dari Proposisi 3.3, diperoleh

$$
\operatorname{det}(\alpha A+\beta E)=\alpha^{n-1}[\alpha \operatorname{det}(A)-\beta \operatorname{det}(A, \mathbf{e})] .
$$

Untuk $\operatorname{det}(A+E)$, berarti $\alpha=1$ dan $\beta=1$. Selanjutnya diperoleh

$$
\begin{aligned}
\operatorname{det}(A+E) & =1^{n-1}[1 \cdot \operatorname{det}(A)-1 \cdot \operatorname{det}(A, \mathbf{e})], \\
& =\operatorname{det}(A)-\operatorname{det}(A, \mathbf{e}) . \\
\operatorname{det}(A, \mathbf{e}) & =\operatorname{det}(A)-\operatorname{det}(A+E) .
\end{aligned}
$$

Proposisi 3.5. Misalkan $A, E \in \mathbb{R}^{n \times n}, n>1$ dan $E=e e^{T}$. Jika A nonsingular maka

$$
\operatorname{det}(A, \boldsymbol{e})=-\boldsymbol{e}^{T} A^{-1} \boldsymbol{e} \operatorname{det}(A)=\frac{(A, \boldsymbol{e})}{A} \operatorname{det}(A) .
$$

Bukti. Matriks saddle point $(A, \mathbf{e})=\left[\begin{array}{cc}A & \mathbf{e} \\ \mathbf{e}^{T} & 0\end{array}\right]$ mengikuti bentuk Schur Complement sedemikian sehingga $\frac{(A, \mathbf{e})}{A}=-\mathbf{e}^{T} A^{-1} \mathbf{e}$.

Berdasarkan Schur Complement, maka diperoleh

$$
\begin{aligned}
\operatorname{det}(A, \mathbf{e}) & =\operatorname{det}\left[\begin{array}{cc}
A & \mathbf{e} \\
\mathbf{e}^{T} & 0
\end{array}\right] \\
& =0-\mathbf{e}^{T} A^{-1} \mathbf{e} \operatorname{det}(A) \\
& =-\mathbf{e}^{T} A^{-1} \mathbf{e} \operatorname{det}(A), \\
& =\frac{(A, \mathbf{e})}{A} \operatorname{det}(A)
\end{aligned}
$$

Proposisi 3.6. Misalkan $A, E \in \mathbb{R}^{n \times n}, n>1$ dan $E=e^{T}$. Jika matriks $A$ nonsingular dan untuk suatu $\alpha, \beta$ di mana $\alpha A+\beta E$ juga nonsingular, maka

$$
\frac{(\alpha A+\beta E, \boldsymbol{e})}{\alpha A+\beta E}=\frac{(A, \boldsymbol{e}) / A}{\alpha-\beta(A, \boldsymbol{e}) / A} .
$$

Bukti. Dari Proposisi 3.2, Proposisi 3.3, dan Schur Complement, diperoleh:

$$
\operatorname{det}(\alpha A+\beta E, \mathbf{e})=\alpha^{n-1} \operatorname{det}(A, \mathbf{e})=\alpha^{n-1} \operatorname{det}(A) \frac{(A, \mathbf{e})}{A} .
$$


Dengan menggunakan Proposisi 3.5 dan Proposisi 3.3, diperoleh

$$
\begin{aligned}
\operatorname{det}(\alpha A+\beta E, \mathbf{e}) & =\frac{(\alpha A+\beta E, \mathbf{e})}{(\alpha A+\beta E)} \operatorname{det}(\alpha A+\beta E), \\
& =\frac{(\alpha A+\beta E, \mathbf{e})}{(\alpha A+\beta E)} \alpha^{n-1}[\alpha \operatorname{det}(A)-\beta \operatorname{det}(A, \mathbf{e})], \\
& =\frac{(\alpha A+\beta E, \mathbf{e})}{(\alpha A+\beta E)} \alpha^{n-1}\left[\alpha \operatorname{det}(A)-\beta\left(\frac{(A, \mathbf{e})}{A}\right) \operatorname{det}(A)\right] .
\end{aligned}
$$

Selanjutnya diperoleh :

$$
\begin{aligned}
\alpha^{n-1} \operatorname{det}(A) \frac{(A, \mathbf{e})}{A} & =\frac{(\alpha A+\beta E, \mathbf{e})}{(\alpha A+\beta E)} \alpha^{n-1}\left[\alpha \operatorname{det}(A)-\beta\left(\frac{(A, \mathbf{e})}{A}\right) \operatorname{det}(A)\right], \\
\frac{(\alpha A+\beta E, \mathbf{e})}{(\alpha A+\beta E)} & =\frac{\alpha^{n-1} \operatorname{det}(A) \frac{(A, \mathbf{e})}{A}}{\alpha^{n-1}\left[\alpha \operatorname{det}(A)-\beta\left(\frac{(A, \mathbf{e})}{A}\right) \operatorname{det}(A)\right]}, \\
& =\frac{\operatorname{det}(A) \frac{(A, \mathbf{e})}{A}}{\operatorname{det}(A)\left[\alpha-\beta \frac{(A, \mathbf{e})}{A}\right]} .
\end{aligned}
$$

Jadi diperoleh

$$
\frac{(\alpha A+\beta E, \mathbf{e})}{(\alpha A+\beta E)}=\frac{(A, \mathbf{e}) / A}{\alpha-\beta(A, \mathbf{e}) / A} .
$$

Berikut ini adalah kajian utama dalam penulisan ini, yaitu teorema mengenai syarat cukup dan syarat perlu keberadaan dan ketunggalan keseimbangan Nash campuran sempurna pada bimatrix games.

Teorema 3.7. Misalkan diberikan suatu bimatrix games simetris $\left[A, A^{T}\right]$, di mana matriks $A_{n \times n}$ adalah matriks pembayaran pemain pertama sedemikian sehingga $(A, e)$ adalah nonsingular. Syarat perlu dan syarat cukup untuk keberadaan dan ketunggalan dari suatu keseimbangan Nash campuran sempurna adalah:

$$
\operatorname{det}\left(A^{i}, \boldsymbol{e}\right) \cdot \operatorname{det}\left(A_{j}, \boldsymbol{e}\right)>0 \text {, untuk semua pasangan } i, j .
$$

Untuk sebarang keseimbangan campuran dalam permainan ini, di mana strategi pemain adalah campuran sempurna, pembayaran $u(A)$ diberikan sebagai berikut:

$$
u(A)=-\frac{\operatorname{det}(A)}{\operatorname{det}(A, \boldsymbol{e})}
$$

dan entri-entri dari vektor peluang $\boldsymbol{y}$ diberikan sebagai berikut:

$$
q_{j}=\frac{\operatorname{det}\left(A_{j}, \boldsymbol{e}\right)}{\operatorname{det}(A, \boldsymbol{e})}, \text { untuk } j=1,2, \cdots, n .
$$

Bukti. Pada suatu keseimbangan Nash di mana strategi-strategi pemain barisnya adalah campuran sempurna, strategi campuran y yang digunakan oleh pemain lain akan memenuhi

$$
\begin{gathered}
A \mathbf{y}=u(A) \mathbf{e} \\
A^{T} \mathbf{x}=u\left(A^{T}\right) \mathbf{e} .
\end{gathered}
$$


Entri-entri pada vektor peluang $\mathbf{y}$ berjumlah 1 . Misalkan $y=\left[q_{j}\right]$, di mana $\sum_{j=1}^{n} q_{j}=1$. Maka

$$
\begin{aligned}
\mathbf{e}^{T} \mathbf{y} & =1, \\
\mathbf{e e}^{T} \mathbf{y} & =\mathbf{e} \cdot 1, \\
E \mathbf{y} & =\mathbf{e}, \text { dengan } E=\mathbf{e e}^{T} .
\end{aligned}
$$

Sehingga diperoleh

$$
\begin{aligned}
u(A) \mathbf{e} & =u(A) E \mathbf{y}, \\
u(A) \mathbf{e}-u(A) E \mathbf{y} & =0, \\
A \mathbf{y}-u(A) E \mathbf{y} & =0, \\
(A-u(A) E) \mathbf{y} & =0 .
\end{aligned}
$$

Entri-entri pada vektor peluang $\mathbf{y}$ adalah strictly positive. Jadi $\mathbf{y}$ bukan vektor nol. Sehingga $\operatorname{det}(A-u(A) E)=0$.

Dengan menggunakan Proposisi 3.3, di mana $\alpha=1$ dan $\beta=-u(A)$, diperoleh

$$
\operatorname{det}(A-u(A) E)=1^{n-1}[1 \cdot \operatorname{det}(A)-(-u(A)) \operatorname{det}(A, \mathbf{e})] .
$$

Selanjutnya diperoleh

$$
\begin{aligned}
\operatorname{det}(A-u(A) E) & =\operatorname{det}(A)+u(A) \operatorname{det}(A, \mathbf{e}), \\
u(A) & =\frac{\operatorname{det}(A-u(A) E)-\operatorname{det}(A)}{\operatorname{det}(A, \mathbf{e})} .
\end{aligned}
$$

Karena $\operatorname{det}[A-u(A) E]=0$, maka

$$
u(A)=-\frac{\operatorname{det}(A)}{\operatorname{det}(A, \mathbf{e})} .
$$

Dalam bentuk matriks, persamaan (3.4) dan persamaan (3.6) dapat ditulis:

$$
\left(\begin{array}{cc}
A & \mathbf{e} \\
\mathbf{e}^{T} & 0
\end{array}\right)\left(\begin{array}{l}
\mathbf{y} \\
0
\end{array}\right)=\left(\begin{array}{c}
u(A) \\
1
\end{array}\right)
$$

Dari aturan Cramer, diperoleh bahwa persamaan (3.6) dan persamaan (3.2) menghasilkan

$$
q_{j}=u(A) \frac{\operatorname{det}\left(A_{j}\right)}{\operatorname{det}(A)}=-\frac{\operatorname{det}(A)}{\operatorname{det}(A, \mathbf{e})}-\left(\frac{\operatorname{det}\left(A_{j}, \mathbf{e}\right)}{\operatorname{det}(A)}\right)=\frac{\operatorname{det}\left(A_{j}, \mathbf{e}\right)}{\operatorname{det}(A, \mathbf{e})},
$$

di mana $q_{j}$ adalah entri-entri dari vektor peluang $\mathbf{y}$.

Argumen yang sama berlaku untuk pemain kolom dan $A^{T}$, karena transposisi dari matriks pembayaran membentuk

$$
\operatorname{det}\left(A^{T}\right)_{j}=\operatorname{det}\left(A^{i}\right)^{T}=\operatorname{det}\left(A^{i}\right), \text { untuk semua } i, j .
$$

Selanjutnya, akan ditunjukkan bahwa keseimbangan Nash ada dan tunggal jika dan hanya jika persamaan (3.1) terpenuhi. Dari persamaan (3.4) jelas bahwa $\mathbf{y}$ adalah tunggal, karena pembayaran $u(A)$ diperoleh dari matriks $A$. Selanjutnya, akan ditunjukkan bahwa keseimbangan Nash campuran sempurna ada. 
$(\Longrightarrow)$ Entri-entri dari vektor peluang $\mathbf{x}$ dan $\mathbf{y}$ adalah $p_{i}=\frac{\operatorname{det}\left(A^{i}, \mathbf{e}\right)}{\operatorname{det}(A, \mathbf{e})}$, dan $q_{j}=\frac{\operatorname{det}\left(A_{j}, \mathbf{e}\right)}{\operatorname{det}(A, \mathbf{e})}$. Misalkan $\exists p_{i}>0, q_{j}>0$ untuk $i, j=1,2, \cdots, n$. Akan ditunjukkan bahwa persamaan (3.1) berlaku. Karena y ada dan tunggal, maka haruslah $\operatorname{det}(A, \mathbf{e}) \neq 0$. Hal ini berarti bahwa $\operatorname{det}(A, \mathbf{e})<0$ atau $\operatorname{det}(A, \mathbf{e})>0$. Pandang dua kasus berikut.

1. $\operatorname{det}\left(A^{i}, \mathbf{e}\right)<0$ dan $\operatorname{det}\left(A_{j}, \mathbf{e}\right)<0$, atau

2. $\operatorname{det}\left(A^{i}, \mathbf{e}\right)>0 \operatorname{dan} \operatorname{det}\left(A_{j}, \mathbf{e}\right)>0$.

(i) Untuk $\operatorname{det}\left(A^{i}, \mathbf{e}\right)=p_{i} \cdot \operatorname{det}(A, \mathbf{e})$ di mana $\operatorname{det}(A, \mathbf{e})<0 \operatorname{dan} p_{i}>0$, diperoleh $\operatorname{det}\left(A^{i}, \mathbf{e}\right)<0$. Untuk $\operatorname{det}\left(A_{j}, \mathbf{e}\right)=q_{j} \cdot \operatorname{det}(A, \mathbf{e})$ di mana $\operatorname{det}(A, \mathbf{e})<0$ dan $q_{j}>0$, diperoleh $\operatorname{det}\left(A_{j}, \mathbf{e}\right)<0$. Sehingga diperoleh

$$
\operatorname{det}\left(A^{i}, \mathbf{e}\right) \cdot \operatorname{det}\left(A_{j}, \mathbf{e}\right)>0 .
$$

(ii) Untuk $\operatorname{det}\left(A^{i}, \mathbf{e}\right)=p_{i} \cdot \operatorname{det}(A, \mathbf{e}) \operatorname{di} \operatorname{mana} \operatorname{det}(A, \mathbf{e})>0 \operatorname{dan} p_{i}>0$, diperoleh $\operatorname{det}\left(A^{i}, \mathbf{e}\right)>0$. Untuk $\operatorname{det}\left(A_{j}, \mathbf{e}\right)=q_{j} \cdot \operatorname{det}(A, \mathbf{e}) \operatorname{dimana}$ $\operatorname{det}(A, \mathbf{e})>0$ dan $q_{j}>0$, diperoleh $\operatorname{det}\left(A_{j}, \mathbf{e}\right)>0$. Sehingga diperoleh

$$
\operatorname{det}\left(A^{i}, \mathbf{e}\right) \cdot \operatorname{det}\left(A_{j}, \mathbf{e}\right)>0 .
$$

Dari persamaan (3.7) dan (3.8)diperoleh persamaan (3.1), yaitu

$$
\operatorname{det}\left(A^{i}, \mathbf{e}\right) \cdot \operatorname{det}\left(A_{j}, \mathbf{e}\right)>0 \text {, untuk semua pasangan } i, j .
$$

$(\Longleftarrow)$ Misalkan $\operatorname{det}\left(A^{i}, \mathbf{e}\right) \cdot \operatorname{det}\left(A_{j}, \mathbf{e}\right)>0$, untuk semua pasangan $i, j$. Akan ditunjukkan bahwa terdapat $p_{i}>0$ dan $q_{j}>0$.

Karena $\operatorname{det}\left(A^{i}, \mathbf{e}\right) \cdot \operatorname{det}\left(A_{j}, \mathbf{e}\right)>0$, maka terdapat dua kemungkinan, yaitu:

1. $\operatorname{det}\left(A^{i}, \mathbf{e}\right)>0 \operatorname{dan} \operatorname{det}\left(A_{j}, \mathbf{e}\right)>0$,

2. $\operatorname{det}\left(A^{i}, \mathbf{e}\right)<0 \operatorname{dan} \operatorname{det}\left(A_{j}, \mathbf{e}\right)<0$.

Karena $\operatorname{det}(A, \mathbf{e}) \neq 0$, maka $\operatorname{det}(A, \mathbf{e})<0$ atau $\operatorname{det}(A, \mathbf{e})>0$. Perhatikan bahwa: $p_{i}=\frac{\operatorname{det}\left(A^{i}, \mathbf{e}\right)}{\operatorname{det}(A, \mathbf{e})} \operatorname{dan} q_{j}=\frac{\operatorname{det}\left(A_{j}, \mathbf{e}\right)}{\operatorname{det}(A, \mathbf{e})}$. Pandang kasus-kasus berikut.

(i) Misalkan $\operatorname{det}\left(A^{i}, \mathbf{e}\right)>0, \operatorname{det}\left(A_{j}, \mathbf{e}\right)>0$, dan $\operatorname{det}(A, \mathbf{e})<0$. Akan ditunjukkan bahwa pada kasus ini, tidak diperoleh $p_{i}>0$ dan $q_{j}>0$. Karena $\operatorname{det}\left(A^{i}, \mathbf{e}\right)>0 \operatorname{dan} \operatorname{det}(A, \mathbf{e})<0$, maka diperoleh $p_{i}<0$. Hal ini tidak mungkin, karena $p_{i}$ haruslah strictly positive. Karena $\operatorname{det}\left(A_{j}, \mathbf{e}\right)>0$ dan $\operatorname{det}(A, \mathbf{e})<0$, maka diperoleh $q_{j}<0$. Hal ini tidak mungkin, karena $q_{j}$ haruslah strictly positive.

(ii) Misalkan $\operatorname{det}\left(A^{i}, \mathbf{e}\right)>0, \operatorname{det}\left(A_{j}, \mathbf{e}\right)>0$, dan $\operatorname{det}(A, \mathbf{e})>0$. Karena $\operatorname{det}\left(A^{i}, \mathbf{e}\right)>0 \operatorname{dan} \operatorname{det}(A, \mathbf{e})>0$, maka diperoleh $p_{i}>0$. Karena $\operatorname{det}\left(A_{j}, \mathbf{e}\right)>0 \operatorname{dan} \operatorname{det}(A, \mathbf{e})>0$, maka diperoleh $q_{j}>0$.

(iii) Misalkan $\operatorname{det}\left(A^{i}, \mathbf{e}\right)<0, \operatorname{det}\left(A_{j}, \mathbf{e}\right)<0$, dan $\operatorname{det}(A, \mathbf{e})<0$. Karena $\operatorname{det}\left(A^{i}, \mathbf{e}\right)<0$ dan $\operatorname{det}(A, \mathbf{e})<0$, maka diperoleh $p_{i}>0$. Karena $\operatorname{det}\left(A_{j}, \mathbf{e}\right)<0 \operatorname{dan} \operatorname{det}(A, \mathbf{e})<0$, maka diperoleh $q_{j}>0$. 
(iv) Misalkan $\operatorname{det}\left(A^{i}, \mathbf{e}\right)<0$, $\operatorname{det}\left(A_{j}, \mathbf{e}\right)<0$, $\operatorname{dan} \operatorname{det}(A, \mathbf{e})>0$. Karena $\operatorname{det}\left(A^{i}, \mathbf{e}\right)<0$ dan $\operatorname{det}(A, \mathbf{e})>0$, maka diperoleh $p_{i}<0$. Hal ini tidak mungkin, karena $p_{i}$ haruslah strictly positive. Karena $\operatorname{det}\left(A_{j}, \mathbf{e}\right)<0$ dan $\operatorname{det}(A, \mathbf{e})>0$, maka diperoleh $q_{j}<0$. Hal ini tidak mungkin, karena $q_{j}$ haruslah strictly positive.

Dari (ii) dan (iii), terbukti bahwa terdapat $p_{i}>0$ dan $q_{j}>0$. Jadi, jika $\operatorname{det}\left(A^{i}, \mathbf{e}\right) \cdot \operatorname{det}\left(A_{j}, \mathbf{e}\right)>0$ maka terdapat $p_{i}>0$ dan $q_{j}>0$.

Jadi terbukti bahwa keseimbangan Nash campuran sempurna ada dan tunggal jika dan hanya jika $\operatorname{det}\left(A^{i}, \mathbf{e}\right) \cdot \operatorname{det}\left(A_{j}, \mathbf{e}\right)>0$.

\section{Kesimpulan}

Pada makalah ini, telah dikaji kembali bahwa Teorema 3.7 dapat diperumum untuk bimatrix games $[A, B]$, di mana matriks $A$ dan $B$ adalah matriks $n \times n$. Diperoleh bahwa syarat cukup dan syarat perlu untuk keberadaan dan ketunggalan dari keseimbangan Nash campuran sempurna adalah bahwa untuk semua pasangan $i, j$, berlaku

$$
\operatorname{det}\left(A^{i}, \mathbf{e}\right) \cdot \operatorname{det}\left(A_{j}, \mathbf{e}\right)>0 \operatorname{dan} \operatorname{det}\left(B^{i}, \mathbf{e}\right) \cdot \operatorname{det}\left(B_{j}, \mathbf{e}\right)>0 .
$$

Untuk pembayaran pemain baris $u(A)$ dan pembayaran pemain kolom $u(B)$ adalah

$$
u(A)=-\frac{\operatorname{det}(A)}{\operatorname{det}(A, \mathbf{e})}, u(B)=-\frac{\operatorname{det}(B)}{\operatorname{det}(B, \mathbf{e})},
$$

dan entri-entri dari vektor peluang $\mathbf{x}$ dan entri-entri dari vektor peluang $\mathbf{y}$ adalah $p_{i}=\frac{\operatorname{det}\left(B^{i}, \mathbf{e}\right)}{\operatorname{det}(B, \mathbf{e})}$, untuk $i=1,2, \cdots, n, \operatorname{dan} q_{j}=\frac{\operatorname{det}\left(A_{j}, \mathbf{e}\right)}{\operatorname{det}(A, \mathbf{e})}, \operatorname{untuk} j=1,2, \cdots, n$.

\section{Ucapan Terima kasih}

Penulis mengucapkan terima kasih kepada Ibu Hazmira Yozza, Ibu Nova Noliza Bakar, dan Ibu Lyra Yulianti yang telah memberikan masukan dan saran sehingga makalah ini dapat diselesaikan dengan baik.

\section{Daftar Pustaka}

[1] Milchtaich, I. and T. Ostrowski. On Some Saddle Point Matrices and Applications to Completely Mixed Equilibrium in Bimatrix Games. http://faculty.biu.ac.il/ milchti/papers/bimatrix.pdf

[2] Ostrowski, T. 2007. A Necessary and Sufficient Condition of a Mixed NE in Bimatrix Games. Int. J. Algebra, Vol. 1. 7 : $303-310$

[3] Ostrowski, T. 2008. On Nonsingularity of Saddle Point Matrices with Vectors of Ones. Int. J. Algebra, Vol. 2. 4 : $197-204$ 